\title{
EMPLOYEES IN TOTAL QUALITY MANAGEMENT
}

\author{
MG MATLHAPE (Wits Health) \& N LESSING (RAU)
}

Companies have become very disillusioned with Total Quality Management (TQM) as a solution to their quality related problems. Part of the problem has been that companies' expectations from TQM is as a solution to their existing problems rather than as a new philosophy towards creating value for shareholders, employees, and customers. Employee involvement is usually the element in the TQM philosophy that is most difficult to manage.

Central to employee participation within the TQM philosophy is teamwork. In the attempt to facilitate total quality management, this article explores specific South African challenges to achieving this. These are

- affirmative action and divers ity management

- skills shortages, training and development

- low levels of employee well-being.

Working with people requires fundamental understanding of the uniqueness of each individual with their own identity and set of preferences. It also requires an understanding of teams and the mechanisms of making a group of individuals work well or poorly together. This will assist managers to realise active participation, quality output from their workers through individualised, and team based motivational processes.

Key words: continuous improvement, employee involvement, employee participation, empowerment, teamwork, Total Quality Management

\section{INTRODUCTION}

People are an essential element of a quality management system. An important component of introducing TQM in an organisation is training, development, and empowerment of personnel, as well as ensuring that quality is not only what employees strive for to make money for shareholders (value creation), but that it becomes a personal goal to them.

Shareholders can, with reasonable certainty, declare full ownership of all physical resources within their organisations. The most important category of the resources of a business, namely employees, however, can never be truly owned. While the actual driving force and the lifeblood of any organisation is its employees, they are the most difficult to mobilise for maximum return on investment for shareholders. The best that an organisation can do is to create an environment that makes the best people want to stay (Pennington 2001:xii).

As the exodus of skilled South Africans moving out of the country gains momentum, a major consideration for organisations becomes the retention of existing talent and the mobilisation of human resources to ensure better service than rivals and gaining competitive advantage in industry. What is required in that instance is a total commitment to quality. This would 
ensure improved output by already committed people as well as an opportunity to motivate the low output, unmotivated staff. Smit $(2000: 117)$ suggests that this can be achieved by means of two strategies. Firstly, by ensuring that quality becomes part of the culture of the organisation, and secondly, by encouraging staff to make quality part of their personal lives.

As Ceronio (1996:312-3) so aptly puts it, the most popular misconception is that the whole economic structure revolves around money. What is missed in these arguments is that markets are made up of people, and the transactional base of society is in fact one of people serving people. This holds true of the symbiotic relationship that exists between employers and employees, their interaction as people in their quest for serving one another and serving the customer. It is also the case in the interaction between employees and their organisation's customers.

This article presents a brief overview of a few TQM models by the major masters and how each sees the component of employee participation as part of TQM. The specific challenges facing South African companies in their quest for service excellence and continuous improvement will then be discussed. The article will conclude with an exploration of the role of employees in TQM, and how this can be maximised by managers. It will also focus on cultural transformation principles that are useful in promoting quality processes and output, and consequently, service excellence in an organisation.

\section{CROSBY'S TEAM WORK}

Crosby outlines fourteen steps as part of an action plan for the improvement of quality in an organisation. In terms of this Ceronio (1996:60) identifies specific steps that specifically involve employees. These are clustered under teamwork and are as follows:

- quality improvement teams

- quality awareness

- employee education

- goal setting

- quality councils.

The early establishment of a quality improvement team is vital to the success of the quality improvement process (Ceronio 1996:62). The quality improvement team is a multi-functional and interdepartmental team whose role is to drive the process as well as to ensure that quality commitment among employees permeates all levels and departments in the organisation. According to James (1996:71) the responsibilities of the quality improvement team includes the following:

- to develop a detailed quality strategy and to action the quality improvement programme.

- to establish the need for resources, monitor results of the programme and make adjustments where necessary.

- to represent their department fully on the team.

- to coordinate and execute quality decisions made by the team as they affect their department. 
- to contribute creatively to the quality programme.

Ceronio (1996:63) adds that quality improvement teams also have a responsibility of developing a complete 14-step implementation plan and to meet regularly to administer the plan and review progress. The team also has the task of assigning each member of the team the responsibility of overseeing one or more of the 14 steps of the implementation plan.

According to Crosby, therefore, the driving force of quality is employees working together as teams- even though quality is defined as a "conformance standard", i.e. regardless if preestablished standards are met or not.

\section{DEMING'S SELF MANAGED TEAMS}

With regard to employees, Deming holds the view that there is a difference between the role of management and the role of employees in a quality system (Ceronio 1996:74). Management is required to provide workers with tools that will enable them to fulfil a job and to continuously improve it. Only if management provides the resources to do the job, will the workers be able to improve the system to produce quality products and services.

Contained in this philosophy, which forms the underlying foundation of Theory $\mathrm{Y}$, is the basic view that one can rely on the work force, that one can trust them, and that if given the responsibility, they will do their best for the organisation (Ceronio 1996:74). According to Deming transformation of an organisation towards a quality organisation is essentially a transformation of management (James 1996:65-66). Quality is what transforms workers into self-managed teams.

\section{EMPLOYEE RELATED CHALLENGES IN TQM}

While TQM was quite popular as a possible solution for companies' poor productivity and quality problems in the 1970 s and 1980 s, Smit (2000:10) claims that this popularity has declined. According to Smit (2000:10), research has shown that there are more incidences where TQM has failed to solve companies' problems than where it has helped them. $\mathrm{He}$ attributes this mainly to limitations of leadership strategies in line with TQM and to reluctant involvement and empowerment of employees in companies. Managers usually focus on employees mainly to elicit desired output, and without real concern for the employee's development or wellbeing.

Employees' role and effectiveness within organisations cannot be seen in isolation of the organisations' cultures, strategies, priorities, and leadership styles. Teifel (1995:48) describes the situation as follows:

Total quality management needs a supportive culture or sentiment within the company to be able to thrive. If the values of this philosophy cannot be installed into the hearts and minds of a company's employees, the chances of long-term success are slim. Also, the values of TQM have to match the actions of its employees, and 
especially its management. As the TQM philosophy is essentially based on the values of openness, trust, exchange, and a "supportive corporate culture", the introduction of a new system in conjunction with an old repressive frame of mind will eventually backfire. Should employees continue to perceive that their problems, feelings, opinions and values are not taken seriously ... then the likelihood of the fundamental tenets being adhered to is drastically imperilled.

In South Africa, and indeed in other parts of the world, some of the phenomena threatening the achievement of these ideals as stated by Teifel (1995:48-9), as well as threatening the ideal of customer delight, quality output and continuous improvement, include the following:

- the management of an increasingly diverse workforce

- the serious shortage of skills in the country and

- the increasing decline in wellbeing among South African workers.

These three phenomena, and how they influence the achievement of total quality management, will be the subject of the next section.

\section{DIVERSITY MANAGEMENT FOR TQM}

As stated above, the TQM philosophy is in essence based on the values of openness, trust, exchange, and a supportive corporate culture (Teifel 1995:48). Workplace tensions, because of unmanaged diversity of workforces, are directly in conflict with the basis of employee involvement in TQM, namely self managed teams.

There is no doubt that at least 50 per cent of the diversity of the workplace came about as a result of the policy of affirmative action, which was strongly encouraged by the government of national unity in the early 1990s. Affirmative action was seen as a mechanism for creating opportunities and structures to allow disempowered groups to develop their educational, political, psychological and economic capacities in a sustainable manner (Dixon 1995:22). This policy was later legalised through the Employment Equity Act of 1998, which identified designated groups as black people, Indian people, coloured people, disabled people, and women of all races. This further increased the extent of diversity in the workplace, which had largely not really dealt with the difficulties associated with affirmative action, preferring to pretend that it was a temporary obstacle that will soon go away.

For example, Dixon (1994:26) showed that in 1993

- only 2 per cent of the total assets in the private sector were owned by blacks

- over 90 per cent of top management positions in the economy were held by whites

- although one out of every seven people in South Africa is white, nine out of ten managers are white.

Apartheid had very obviously entrenched itself within the business sector, and business had to manage it decisively. Only a few companies saw this as an opportunity to create a competitive advantage. Instead, the bulk of the companies introduced a range of tokenist models while essentially keeping the status quo. These are among the reasons that there 
are such diversity tensions in the workplace presently, and that these tensions are now a serious threat to TQM.

\section{DIVERSITY AFFECTS QUALITY}

Largely, there is still a perception among black people, especially the black labour movement, that the wealth of the country belongs to whites, so motivation for quality is perceived as making the white man richer. On the other hand, workplace cultures are dominated by western ways, resulting in opportunities lost for the development of unique systems and processes based on a combination of western and African cultures. This remains a major hurdle to using a combination of diversity and quality as a competitive advantage in the global markets.

As more and more employees spend a big part of their waking hours in the workplace, it becomes important that relationships in the workplace receive as much respect as relationships outside work. This is an imperative for the success of teamwork, self managed teams, and quality circles as defined in the beginning of this article.

\section{SKILLS SHORTAGE}

In 1995, the average growth in remuneration for South African employees was 15 per cent, with a corresponding productivity increase per annum of 1 per cent. Compared to the G7 countries, where remuneration grew by 7.5 per cent and productivity increased by 2.7 per cent, these figures were highly alarming for an economy that was striving for active participation on global markets. The sources of low productivity are not only related to wages, but also include the lack of technical and management skills (Finnemore 1997:55).

Skills shortage is another major challenge for South African business, especially in the manner in which it influences the implementation of affirmative action. The greatest barrier to the real implementation of affirmative action is white managers' fear that it will result in "the dropping of standards" (Dixon 1994:6). Redressing disadvantages implies active training and other programmes directed at disadvantaged groups so that they can compete on an equal footing with their privileged counterparts.

This is part of the reason that the South African government introduced the Skills Development Act and its sister legislation, the Skills Development Levy Act. The relevance of the legislation to TQM is that both acts are intended to turn South Africa into a learning nation, helping companies to enhance organisational performance and helping South Africans to acquire skills that will help them to actively participate in building the economy.

Training and development of employees is thus an important element of total quality management. Apart from all the national priorities that justify training and skills development, employees who have the tools to do their jobs efficiently will find work more satisfying, and their managers will find their work a little easier (Franco 2000:Internet). 


\section{EMPLOYEE WELLBEING}

The human resources focus of performance excellence has as its main components: work systems, employee education, training and development, as well as employee wellbeing and satisfaction (Ross 1999:133-4). Employee wellbeing can therefore not be ignored when discussing elements that quality-focused companies must mobilise in order to achieve excellence.

The mental capacity to do productive work is under attack from a complicated network of social, economic, biological and genetic forces. Employee wellbeing is thus an important business productivity weapon. Organisations that promote employee wellbeing enhance their own competitive position by promoting the mental output of workers. Emotional work hazards, like loss of control over one's job, haphazardly altered priorities at work, office politics, uncertainty about jobs, high performance expectations but low rewards, are psychosocial factors which have more impact on employee health than given credit for. Stress can have a detrimental effect not only on the health of employees but also on their capacity for physical and mental output. When exploring the role of employees in promoting TQM, therefore, it is imperative that some time is spent in establishing that stress is indeed an enemy towards the achievement of its main principles.

\section{Stress can hurt business}

Links have been established between stress and the incidence of coronary heart disease, alcoholism, mental breakdown, poor health behaviours, job dissatisfaction, accidents, family problems and certain forms of cancer (Berridge, Cooper \& Highley-Marchington 1997:1).

Stress hurts business. For UK companies in the 1980s, stress in the workplace was ten times more costly than industrial relations disputes. In 1995, alcohol and drink related diseases cost the UK economy approximately 1.7 billion annually and 80 million lost working days, with coronary artery diseases and strokes costing the economy a further 62 million lost days. In the same period mental ill health was calculated at $£ 3.7$ billion and 91 million days lost (Berridge, Cooper \& Highley-Marchington 1997:2). In 2000, the cost of alcohol misuse to British industry had escalated to £2.39 billion through the cost of sickness, early death and unemployment (ICAS 2001: Internet). ICAS also reports that 75 per cent of all people with alcohol problems are employed, and that 46 per cent of large companies report alcohol problems in the workplace.

The United States National Institute for Occupation Safety and Health reports that stress related disorders are quickly becoming the most prevalent reason for worker disability. In 1992, the United Nations identified job stress as a $20^{\text {th }}$ century worldwide epidemic. Here is some more statistical evidence to the fact that stress is a serious economic and workplace problem, as outlined by Borcherds (2000:4):

- Research shows that at least 40 per cent of employee turnover in the United States is due to on the job stress. Xerox estimates that it costs between $\$ 1,0$ to $\$ 1,5$ million to replace a top executive, and between $\$ 2000$ and $\$ 13000$ to replace other workers.

- The international Survey Research Corporation in Chicago has carried out polls measuring low morale at work due to loss of faith in the employer. In 198822 per cent of 
those polled said that they were "frequently worried" about losing their jobs, and in 1996 the percentage of those giving the same response rose to 46 per cent.

- Job stress is estimated to cost the American industry $\$ 200$ to $\$ 300$ billion annually due to related factors such as absenteeism, diminished productivity, employee turnover, accidents, direct medical, legal and insurance fees, and workman's compensation awards.

- The United States Bureau of Labour Statistics has identified "neurotic reaction to stress" as the $4^{\text {th }}$ most prevalent disabling workplace injury. In 1993, on average, over 25 workdays were lost by each person suffering from job stress.

- In 1997 the British Medical Journal sited two studies that have shown that job stress may increase chances of coronary heart disease.

- In Japan, "Karoshi", which means death from overwork, is now recognised as a fatal combination of apoplexy, high blood pressure and stress.

- The National Institute for Occupational Safety and Health found that 25 per cent of those surveyed identified their job as the single greatest cause of stress in their lives.

- Job stress can be both a cause and an effect of workplace violence.

In South Africa, although reliable statistical information is not available, the situation is much worse than in the developed countries. The extremely high rate of retrenchments and closure of established companies has made job insecurity a major cause of stress both in the workplace and in employees' private lives. The escalating rate of crime can be linked as both a cause and result of economic factors. The importance and cost of stress is brought home constantly to the employer in the size of health care medical aid premiums and the rate of their annual increase.

The lack of trust and companionship among employees from diverse cultures is still a source of great distress in the workplace, and largely affects the employees' sense of worth within the work environment. The active transformation of labour legislation since 1995, while it has good intentions as a basis, is often misunderstood as purely racially driven and result in tensions that often exacerbate the problem.

In its quest to obtain World Trade Organisation approval and globalisation status, South Africa, like most developing countries, has relentlessly pursued an economic policy that is obviously sensible in the long-term but is coming at high cost to the nation in the short term. With the privatisation of most state owned assets, job losses in state enterprises have averaged 25 to 40 per cent in the past three years. Needless to say, the country's inability to create jobs at a rate even less than half of the rate that it is shedding jobs, is a source of great distress for the economically active population.

It is not only job-related stress that affects productivity in the workplace. General absence of wellbeing brought about by work related and unrelated factors are detrimental to productivity. The uncontrolled escalation of HIV infection is already having serious impacts in the workplace. By 2005, absenteeism from work and low productivity will be attributable mainly to HIV and Aids related factors. This will be through sickness, emotional problems attributable directly to the HIV status (e.g. stigma by fellow employees, fear of death, shame, guilt). The scourge of HIV and Aids is beginning to have serious impact on the emotional and physical wellbeing of South Africans, whether as direct sufferers or as family members 
or friends or acquaintainces of sufferers. This is a major source of stress in the workplace and cannot be ignored.

\section{The impact of stress on the economy}

It is not only the employer who suffers the consequences of stress but generally, the cost of stress for the nation is also currently extremely high. The South African Heart Foundation estimates that 360000 people die in South Africa each year from coronary heart disease, i.e. almost 1000 people a day. In addition, the South African Federation for Mental Health estimates that between 40 per cent and 50 per cent of all sickness absence from work is attributable to mental and emotional disturbance.

The country has also suffered from increased rates of suicide amongst the young. While there are no clear statistics from hospitals and Statistics South Africa, mental health societies estimate an increase of 30 per cent since 1990. The instability of the South African society and life stress have led to annual divorce rates trebling since the late 80's, and the rise is still continuing. The Family and Marriage Association of South Africa estimates that by 2005 one out of every three marriages in South Africa will end in divorce. The South African National Council estimates the rate of abuse and dependence on alcohol at an increase of 20 per cent per annum for Drug Dependence and Alcohol Abuse. Along with these statistics is the escalation of the rate of abuse of women and children, the rate of violent crimes, family murders, road rage and an untold number of other social ills. Not only is the South African society in general suffering from stress, but also South African companies are carrying very high costs as a result of the consequences of the stress in the workplace.

Since stress represents a major drain on the economy in costs to the health system, in lost productivity, and in many social agency and transfer costs, it makes eminent sense for the industry to deal with the problem on its own ground and in its own terms.

Employee assistance programmes are work-based programmes designed to assist in the identification and resolution of productivity problems associated with employees that are impaired by personal and work related concerns. These programmes present an opportunity for the employer to manage and control work stress and its resultant problems.

\section{MANAGING EMPLOYEES WITHIN TQM PHILOSOPHY}

A great deal of work has been done on motivation of people. Among them there is the classical work of Maslow (1954), with his theory of the hierarchy of needs as a motivator; Herzberg (1966), who distinguishes between motivators and hygiene factors; and McGregor (1960), who claims that people are motivated by their dominant need among the need for power, need for affiliation, and need for achievement. These theories are useful in the basic understanding of behaviour usually occurring for a reason, and that understanding this reason would help managers to influence behaviour to a certain extent.

The general limitation of all these theories is that they do not take enough cognisance of the fact that people are different. They generalise motivators as if people are either motivated by one thing or another. 
Cartwright (1999:41-67) proposes nine key motivating factors for continuous improvement. These are listed below.

- Identification which defines the uniqueness of each individual .

- Equity which refers to a balance between expectations and rewards.

- Equality refers to the fact that while not all employees can be treated equally, everyone should be treated with respect irrespective of status .

- Consensus is an arrival at a mutual understanding, underscoring the importance of teamwork in quality.

- Instrumentality which is a means by which to achieve an objective.

- Rationality which introduces the idea of a scientific approach to management.

- Development which refers to continuous improvement of an organisation through the development of its people.

- Group dynamics refers to intra group relationships within a group, and inter group relationships between groups.

- Internalisation of cultural beliefs and value as the most powerful and permanent motivating factor.

In the understanding of the nine factors as motivators, Cartwright $(1999: 44)$ cautions that motivation has two directions, namely the positive direction, which is to attract, and the negative direction, which is to repel. Between these two forces is indifference

Employee participation is a central pillar that holds TQM in world-class organisations together. Smit $(2000: 86)$ quotes some of the advices by the well-known TQM gurus in relation to employees. For example, Juran \& Gryna (1980:147) assert that companies must "improve communication to understand better how things look to the workers". Crosby (1992:34) advices organisations to "generate a culture built on respect for the individual, display consistency in policy and purpose, provide and encourage education for all, and lay out a clear opportunity for growth". Masujima (1993) proposes that employers should "continually invest in human resources and involve all employees".

Managers can, on their own, contribute nothing of value to their organisations' customers. They create value in so far as they give service providers and frontline workers the ability to do their work (Smit 2000:90). On the other hand, employees can be custodians of TQM in organisations. To do that, they have to take responsibility for the implementation of TQM as a strategy of their organisations; share in the organisational goals; and invest their talents within the organisation to achieve the team's and organisation's success.

\section{EMPLOYEES' ROLE IN IMPLEMENTING TQM AS AN ORGANISATIONAL STRATEGY}

TQM goes far beyond the philosophy and practices of quality control and quality assurance. It is a strategy that is concerned with changing the fundamental beliefs, values and cultures of the organisation, harnessing the enthusiasm of, and participation by everyone towards an overall idea of "right first time" (Ceronio 1996:21). 
To achieve the ideals of TQM, employees have to understand it as a corrective and developmental strategy for the good of all stakeholders in the organisation. This will involve the employees participating in processes of reengineering, new ways of doing things, and communicating their ideas to management. For employees to practise this level of commitment and involvement, it is imperative that management consciously transfer skills and the power to take necessary decisions, to them. Workers must believe that management genuinely trusts them with the custodianship for quality achievement and continuous improvement.

If the quality movement is to have truly widespread success, it must convince managers to see the merits of the prospect that there must be less control and more freedom. They must learn that managing is not merely controlling, but unfortunately their egos and fear all too often make it impossible for them to let go of power (Smit 2000:87).

Employees also have the responsibility to identify quality defects, as well as to proactively recognise threats to quality and continuous improvement. To be able to do this, employees need to have no fear of reprimand or discipline from management for failing to achieve total quality. Managers need to create a culture of learning and freedom to make mistakes in the process of learning.

Cartwright (1999:59) suggests that employers create a culture of development as a means of encouraging learning within an organisation. This can be accomplished in two ways:

- Training people for the task so that they can better serve the organisation through improved skills and methods and increased knowledge.

- Education for the person to develop flexible and adaptable individual capabilities through learning, understanding and growing.

Development, therefore, is a process of mutual improvement, to the benefit of the individual and the organisation.

Cartwright (1999:61) identifies the following practices as essential in the use of the culture of learning to develop people and organisations:

- As productivity per employee increases individual development becomes more important.

- Motivation through development requires recruitment and training for attitude and aptitude.

- The organisation develops itself through the development of its people.

- Ownership, empowerment and autonomy cascade through the organisation.

- Managers deal with mistakes and problems as an opportunity to develop their people.

- Psychological development results in improving attitudes and behaviour.

- Positive attitudes, morale and motivation are essential to the developing organisation.

- As shopfloor autonomy increases, so managers should develop themselves trough broader education.

People are very important in the implementation of service quality strategies for organisations. All the human actors participating in the delivery of a service, provide cues to the customer regarding the nature of the service itself. How these people are dressed, their personal appearance, and their attitudes and behaviours, all influence the customer's 
perceptions of the service. In some services, like counselling, consulting, or auditing, the provider in person is the service (Zeithaml \& Bitner 1996:26). In the service industry in particular, but in product-based industries as well, the organisation is completely dependent on employees to communicate the value placed on the customer by the company, through service delivery. As stated by Zeithaml \& Bitner (1996: 26), contacting service providers may be the focal point of service encounters that can prove critical for the organisation.

\section{EMPLOYEES’ ROLE IN SHARING IN THE ORGANISATIONAL GOALS}

When they join organisations, employees usually enter into a service contract, where they commit to abide by the organisational rules and regulations. This contract is useful as a foundation for the nature of the relationship that will develop between the employer and the employee. This relationship tends to be rules-based as well as tending to focus on minimum standards. Organisations of the $21^{\text {st }}$ century have to focus beyond minimum standards, to developing teams based on excellence.

Excellence requires that employees must identify a benefit for themselves in the achievement of organisational goals. This benefit is not always measured in terms of remuneration. Branham (2000:54) believes that people want more than just material rewards. They want to believe that their jobs are vital to the company's success. Cartwright (1999:54) proposes a motivational tool that he refers to as instrumentality to motivate employees to achieve desirable goals for the company, and to avoid undesirable outcomes.

According to Cartwright (1999:54), instrumentality happens in two directions:

- feed forward, which is to be motivated by goals, objectives and expectations

- feedback, which is to give recognition and encouragement for efforts made or to give admonishment when things are not happening as they should.

How successful an organisation is will depend on the commitment of its people to achieve the goals that an organisation has set for itself. The ideal is that individuals within the organisation also set goals for themselves that coincide with organisational goals, so that employees can be motivated by them. For example, it has been found that there is a mutual relationship between employee satisfaction and customer satisfaction, where satisfied customers can reinforce the employees' sense of satisfaction in their jobs (Ziethaml \& Bitner 1996:304).

Another motivator suggested by Cartwright (1999:44) in encouraging people to share in the organisational goals is identification. Personal identity is the most important thing that humans possess. It is the way humans feel about themselves, the way they express themselves, and the way other people see them. This is the core of what makes individuals unique (Cartwright 1999:44). The realisation of the importance of this identity for managers is fundamental for people management. People like to be recognised for what they are, what they uniquely possess, and what their specific contribution can add to business. This is a major motivator towards continuous improvement and total quality. 
Identification is also a motivator in so far as individuals can identify attractive attributes in a leader that encourages them to use them as a role model. In the same way, unattractive leadership may repel and act as a demotivator for employees (Cartwright 1999:45). Similarly, employees will identify more readily with an organisation that shares the same values and beliefs as themselves. For example, employees who regard themselves as caring, reliable and honest, may find it difficult to identify with a job that requires them to carry out industrial espionage.

In terms of the factor of identification, employers have to take time to understand each individual in the company and treat each one as a unique person. In the same way, leadership has to work on developing a company whose vision, mission, and values build its image. People would commit themselves more readily to a company with which they can identify themselves. Branham (2000:58-9) cautions that managers should be able to identify the difference between commitment and compliance. He suggests that employees should not only be expected to identify with a company's vision and mission, they should as much as possible participate in developing one.

\section{EMPLOYEES' ROLE IN INVESTING THEIR TALENTS FOR THE BENEFIT OF THEIR TEAMS AND THE ORGANISATION}

As the market within which organisations do business, become increasingly more sophisticated, the demand for sophisticated skills is also increasing. Most organisations create an opportunity for employees to develop skills, at least to be able to meet the demands of their jobs. According to Branham (2000:24-5) this is not enough. Employers have to create a culture that will make employees want to invest their talents within an organisation over a reasonable period. As talent and skill becomes more rare, employers find themselves involved in what Branham (2000:1) refers to as "the war for talent".

One of the ways of winning the war for talent, as identified by most TQM gurus, is the team approach. Teams are a very important TQM output vehicle as varying styles, interests and skills of employees are used to complement one another for the achievement of team goals and thereby organisational goals. Within the team, feelings of belonging, sharing, togetherness, caring and friendliness, create an enjoyable working atmosphere with the mutual support and cooperation that helps to reduce the pressures and stress on individual members, especially the group leaders.

Cartwright (1999:47-54) identifies organisational cultures of equity, equality and consensus as very important, especially where there are differences in the personal backgrounds of employees working within a team. These differences may be in social circumstances, ethnicity and education. They may also be in personalities, values, and work styles. "Positive group motivations are created through individual loyalty to the group, consensus, and a mutual sharing of and commitment towards achieving group goals. Negative group motivations are caused by such things as conflicts between group members, a clash of personalities, divided loyalties, favouritism for some and prejudice against others" (Cartwright 1999:62). 
Employees have a responsibility to invest their talents within their organisations, making an effort to share in organisational goals, and actively working towards the implementation of the company strategy. On the other hand, employers have to take responsibility for the maximisation of employee's productivity, striving for commitment rather than compliance, and respecting the employees' need to make a difference.

\section{CLOSURE}

As global competitiveness escalates, companies' awareness of the cardinal role played by employees in creating a competitive advantage is improving. A great deal of work has still to be done to transform the culture of workplaces to more respectful equitable and cohesive institutions. The potential of workers remains locked up in the management styles of their managers. Largely, managers still do the thinking while workers do the implementation of their thoughts. Full involvement of employees, in all their diversity, in continuous improvement is the key to the successful implementation of TQM.

\section{BIBLIOGRAPHY}

BERRIDGE J, COOPER CL \& HIGHLY-MARCHINGTON C. 1997. Employee Assistance Programmes and workplace counselling. New York: Wiley.

BORCHERDS M. 2000. Mental health in the workplace: a strategy for mental health societies. Johannesburg : South African Federation for Mental Health. [Biennial conference.]

BRANHAM L. 2000. Keeping the people who keep you in business: 24 ways to hang on to your most valuable talent. New York: Amacom.

CARTWRIGHT J. 1999. Cultural transformation: nine factors for continuous business improvement. London : Prentice Hall.

CERONIO SF. 1996. Achieving Total Quality Management in a South African manufacturing environment. Johannesburg : RAU. (D Com-thesis).

DIXON WAG. 1994. Affirmative Action: The perfect excuse or the perfect opportunity. Johannesburg : RAU. (Certificate: Advanced Business Management - short dissertation).

FINNEMORE M. 1997. Introduction to labour relations in South Africa $5^{\text {th }}$ ed. Durban: Butterworths.

FRANCO VR. 2001. Training outside the box: a quality manager's guide to training. [URL Address: http://www.qualitydigest.com/currentmag/html/training.html].

HERZBERG F. 1966. Work and the nature of man. New York : William Collins.

ICAS SEe INSTITUTE FOR CHARTERED ACCOUNTANTS OF SCOTLAND. 
INSTITUTE FOR CHARTERED ACCOUNTANTS OF SCOTLAND. 2001. Special report: alcohol misuse. [Internet: www.icas.org.uk/sr/alcohol.]

JAMES P. 1996. Total Quality Management: an introductory text. London : Prentice Hall.

MASLOW AH. 1954. Motivation and personality. New York : Harper \& Row.

McGREGOR D. 1960. The human side of an enterprise. New York : McGraw-Hill.

PENNINGTON S. 2001. Human capital strategies for the $21^{\text {st }}$ century. Rivonia : SPA.

ROSS J E. 1999. Total Quality Management: text, cases and readings. Washington DC : St Lucie.

SMIT DBH. 2000. Total Quality Management: a strategic management approach Johannesburg : RAU. (D Com-thesis).

TEIFEL HHH. 1995. Corporate culture: a potential hurdle to Total Quality Management Johannesburg: RAU. (M Com-dissertation).

ZEITHAML VA \& BITNER MJ. 1996. Services marketing. $2^{\text {nd }}$ ed. New York : McGraw-Hill. 